\title{
Primary basilar invagination
}

INSERM

\section{Source}

INSERM. (1999). Orphanet: an online rare disease and orphan drug data base. Primary basilar invagination. ORPHA:2285

Primary basilar impression (PBI) is a very rare skeletal developmental defect characterized by congenital upward translocation of the upper cervical spine and clivus into the foramen magnum. PBI can be asymptomatic or associated with severe neurological dysfunction. 